\title{
Effects of small doses of ouabain on the arterial blood pressure of anesthetized hypertensive and normotensive rats
}

L.V. Rossoni,

V.D. Pinto and

D.V. Vassallo
Departamento de Ciências Fisiológicas, Universidade Federal do Espírito Santo, Vitória, ES, Brasil

\section{Correspondence}

D.V. Vassallo

Departamento de Ciências

Fisiológicas, CBM, UFES

Av. Marechal Campos, 1468

29040-095 Vitória, ES

Brasil

Fax: + 55-27-335-7330

E-mail: daltonv2@ terra.com.br

Research supported by CNPq and FINEP.

Received April 24, 2000 Accepted May 18, 2001

\section{Abstract}

Ouabain increases vascular resistance and may induce hypertension by inhibiting the $\mathrm{Na}^{+}$pump. The effects of 0.18 and $18 \mu \mathrm{g} / \mathrm{kg}$, and $1.8 \mathrm{mg} /$ $\mathrm{kg}$ ouabain pretreatment on the phenylephrine (PHE; 0.1, 0.25 and 0.5 $\mu \mathrm{g}$, in bolus)-evoked pressor responses were investigated using anesthetized normotensive (control and uninephrectomized) and hypertensive (1K1C and DOCA-salt treated) rats. Treatment with $18 \mu \mathrm{g} / \mathrm{kg}$ ouabain increased systolic and diastolic blood pressure in all groups studied. However, the magnitude of this increase was larger for the hypertensive $1 \mathrm{~K} 1 \mathrm{C}$ and DOCA-salt rats than for normotensive animals, while the pressor effect of $0.18 \mu \mathrm{g} / \mathrm{kg}$ ouabain was greater only in DOCA-salt rats. A very large dose $(1.8 \mathrm{mg} / \mathrm{kg})$ produced toxic effects on the normotensive control but not on uninephrectomized or $1 \mathrm{~K} 1 \mathrm{C}$ rats. Rat tail vascular beds were perfused to analyze the effects of $10 \mathrm{nM}$ ouabain on the pressor response to PHE. In all animals, $10 \mathrm{nM}$ ouabain increased the PHE pressor response, but this increase was larger in hypertensive DOCA-salt rats than in normotensive and $1 \mathrm{~K} 1 \mathrm{C}$ rats. Results suggested that a) increases in diastolic blood pressure induced by $18 \mu \mathrm{g} / \mathrm{kg}$ ouabain were larger in hypertensive than normotensive rats; b) in DOCA-salt rats, smaller ouabain doses had a stronger effect than in other groups; c) hypertensive and uninephrectomized rats were less sensitive to toxic doses of ouabain, and d) after treatment with $10 \mathrm{nM}$ ouabain isolated tail vascular beds from DOCA-salt rats were more sensitive to the pressor effect of PHE than those from normotensive and $1 \mathrm{~K} 1 \mathrm{C}$ hypertensive rats. These data suggest that very small doses of ouabain, which might produce nanomolar plasma concentrations, enhance pressor reactivity in DOCA-salt hypertensive rats, supporting the idea that endogenous ouabain may contribute to the increase and maintenance of vascular tone in hypertension.

\section{Introduction}

Previous reports have shown that ouabain pretreatment of normotensive rats enhances arterial blood pressure and vasopressor responses to vasoconstrictor agents in vivo and in vitro $(1,2)$. In vivo, the sensitiza-
Key words

- Pressor reactivity

- Ouabain

- Phenylephrine

- $1 \mathrm{~K} 1 \mathrm{C}$ rats

- DOCA-salt

- Uninephrectomy 
were not enough to induce the same effect in normotensive rats (1).

In vitro, we also demonstrated that both $100 \mu \mathrm{M}$ and $10 \mathrm{nM}$ ouabain enhance the vasoactive responses elicited by phenylephrine in rat tail arteries $(1,2)$. In these preparations the enhancement of the vasoconstrictor responses to phenylephrine was greater in SHR (1).

The sensitization produced by ouabain is caused by the inhibition of the $\mathrm{Na}^{+}$pump (3). A reduction in $\mathrm{Na}^{+}$pump activity leads to $\mathrm{Na}^{+}$accumulation in the myoplasm (4). The $\mathrm{Na}^{+}$increment affects the $\mathrm{Na}^{+} / \mathrm{Ca}^{2+}$ exchange mechanism and consequently increases the amount of activator $\mathrm{Ca}^{2+}$ necessary for contraction of vascular smooth muscle $(4,5)$. Therefore, disturbances in such mechanisms can produce contractile changes, which may be relevant for arterial blood pressure homeostasis. Indeed, the consequence of the inhibition of the sarcolemmal $\mathrm{Na}^{+}$pump is an enhanced responsiveness of vascular smooth muscle to constrictor agents (2).

It is now known that all three isoforms of the $\mathrm{Na}^{+}, \mathrm{K}^{+}$-ATPase $\alpha$ subunit have distinct sensitivities for cardiac glycosides and all are expressed in rat tail arteries and aorta (6). The presence of high-affinity isoforms in the vasculature raises the possibility that, even at low levels, endogenous ouabain may act as a modulator increasing tone or pressor responses to endogenous vasoactive agents (5). This possibility is reinforced by the description of ouabain as an endogenous compound existing in human plasma (7) and in several other animal species $(8,9)$.

The purpose of the present study was to determine whether ouabain at concentrations similar to the endogenous ones can increase vascular tone and enhance phenylephrineinduced vasoconstriction in vivo and in vitro in normotensive control, uninephrectomized, hypertensive one kidney, one clip (1K1C) rats and in deoxycorticosterone acetate (DOCA)-salt rats.

\section{Material and Methods}

\section{Experimental animals}

Studies were performed on 129 male Wistar rats weighing 200 to $380 \mathrm{~g}$, divided into five main groups: 22 control rats (normotensive rats), 58 uninephrectomized rats, 21 DOCA-salt-treated rats, and $281 \mathrm{~K} 1 \mathrm{C}$ rats. The care and use of the laboratory animals were in accordance with NIH guidelines. All rats had free access to water and rat chow ad libitum.

\section{Hypertension models}

Renovascular hypertension. With rats under ether anesthesia, renovascular hypertension (Goldblatt 1K1C model) was produced by application of a silver clip (0.2-mm internal diameter) to the left renal artery, combined with nephrectomy of the right kidney through an abdominal incision. Weightmatched control rats were uninephrectomized and submitted to right-side nephrectomy without the clip application. After these procedures, muscle layers were reconnected, and the skin incision was closed. Rats were placed in plastic cages with supplies of water and chow for 30 days.

DOCA-salt hypertension. Male 45-dayold rats were uninephrectomized under ether anesthesia. Four days later the animals were treated with either DOCA (8 $\mathrm{mg} / \mathrm{kg}$ twice a week) or vehicle (soybean oil, $0.25 \mathrm{ml} /$ animal). This treatment was repeated twice a week for 30 days. The vehicle-treated uninephrectomized rats drank water and the DOCA-salt rats drank saline solution $(0.9 \% \mathrm{NaCl})$ during the treatment.

The day before the experiments the systolic blood pressure of all rats was measured using a tail-cuff method (IITC Model 29 Pulse Amplifier, IITC Inc., Santa Barbara, CA, USA). Animals which did not develop hypertension were excluded. 


\section{Anesthetized animals}

At the end of the treatments, rats were anesthetized with urethane $(1.8 \mathrm{~g} / \mathrm{kg}$, ip $)$, supplemented when necessary. The jugular vein and the carotid artery were dissected and cannulated with a polyethylene catheter (PE-50 with heparinized saline) for drug infusion and arterial blood pressure measurements, respectively. Arterial blood pressure was measured with a pressure transducer (Gold P23XL) connected to an MP 100 amplifier (FUNBEC, São Paulo, SP, Brazil) and recorded on a polygraphic recorder (RG 300, FUNBEC). ECG was also measured using standard procedures.

The following protocol was used for all groups. Pressor reactivity was investigated by measuring arterial blood pressure and by injecting $(i v)$ increasing doses of phenylephrine $(0.1,0.25$ and $0.5 \mu \mathrm{g})$ administered in small volumes ( $5 \mu \mathrm{l}$ or less) before and $1 \mathrm{~h}$ after ouabain treatment. All groups of rats were divided into three subgroups and each subgroup was treated with either $0.18 \mu \mathrm{g} / \mathrm{kg}, 18$ $\mu \mathrm{g} / \mathrm{kg}$ or $1.8 \mathrm{mg} / \mathrm{kg}$ ouabain. Ouabain treatments were employed based on the human loading doses, but taking into consideration that the rat is more resistant to ouabain. In humans, acute digitalization with ouabain is obtained with 4 to $5 \mu \mathrm{g} / \mathrm{kg}$. We then administered ouabain covering the range of toxic (1.8 $\mathrm{mg} / \mathrm{kg})$ and non-toxic doses $(18 \mu \mathrm{g} / \mathrm{kg})$, including a very small dose $(0.18 \mu \mathrm{g} / \mathrm{kg})$ which is expected to produce plasma concentrations at the nanomolar level. Systolic and diastolic blood pressure and the ECG were monitored continuously for heart rate evaluation.

Isolated rat tail vascular bed preparation. Isolated rat tail vascular beds were used in this study as previously reported (10). Briefly, the rats were anesthetized with sodium pentobarbital $(65 \mathrm{mg} / \mathrm{kg}$, ip $)$ and heparin $(500 \mathrm{IU}, i p)$ was administered after loss of the righting reflex. Ten minutes after the administration of heparin, $1 \mathrm{~cm}$ of the tail artery was dissected free and cannulated with an intracath (Gelco 24) near the base of the tail. The vascular bed was flushed with Krebs-Henseleit buffer (KHB) (120 mM $\mathrm{NaCl}, 5.4 \mathrm{mM} \mathrm{KCl}, 1.2 \mathrm{mM} \mathrm{MgCl}_{2}, 1.25 \mathrm{mM}$ $\mathrm{CaCl}_{2}, 2.0 \mathrm{mM} \mathrm{NaH}_{2} \mathrm{PO}_{4}, 27 \mathrm{mM} \mathrm{NaHCO}_{3}$, $11 \mathrm{mM}$ glucose, and $0.03 \mathrm{mMEDTA}$ ) bubbled with $5 \% \mathrm{CO}_{2}-95 \% \mathrm{O}_{2}$ at $36 \pm 0.5^{\circ} \mathrm{C}$. The tail was then severed from the body and placed in a tissue bath and perfused with KHB at a constant flow of $2.5 \mathrm{ml} / \mathrm{min}$ with a peristaltic pump (Milan, Colombo, PR, Brazil). After a 30- to 45-min equilibration period, the experimental protocol was initiated. Mean perfusion pressure was measured with a pressure transducer (TP-200T, Nihon-Kohden connected to an MP-100 pressure amplifier, FUNBEC) and the data were recorded using an interface and software for computer data acquisition, BIOPAC MP100A (Biopac System, Inc., Santa Barbara, CA, USA) with a sample rate of $500 \mathrm{~Hz}$ per channel. Because a constant flow was maintained, changes in the perfusion pressure represented changes in vascular resistance. The following protocol was used.

After $30 \mathrm{~min}$ stabilization bolus injections of increasing doses of phenylephrine $(0.5,1,2,5$ and $10 \mu \mathrm{g}$, in $100 \mu \mathrm{l})$ were administered in the absence or in the presence of $10 \mathrm{nM}$ ouabain. The second doseresponse curve was constructed $1 \mathrm{~h}$ after continuous infusion of KHB containing 10 $\mathrm{nM}$ ouabain. At the end of the experiment, preparations were contracted by continuous infusion of phenylephrine (100 nM) and endothelial integrity was tested using bolus injection of acetylcholine $(5 \mu \mathrm{g}$ in $100 \mu \mathrm{l})$. Endothelial integrity of the preparations was considered adequate when relaxation in response to acetylcholine attained $50 \%$ or more. This protocol was performed in preparations from normotensive (control, $\mathrm{N}=6$, and uninephrectomized, $\mathrm{N}=8$ ) and hypertensive (1K1C, $\mathrm{N}=7$, and DOCA-salt, $\mathrm{N}=7$ ) rats.

\section{Statistical analysis}

Results are reported as means \pm SEM. 
Results regarding perfusion pressure measurements are presented as changes in the mean perfusion pressure calculated by subtracting peak pressure from baseline pressure. Data were analyzed by the Student $t$ test and ANOVA. When the ANOVA showed a significant treatment effect, the Tukey post hoc test was used to compare the different treatment groups. The level of significance was set at $\mathrm{P}<0.05$.

\section{Drugs and reagents used}

Deoxycorticosterone acetate, urethane, L-phenylephrine hydrochloride, acetylcholine chloride, and ouabain octahydrate were purchased from Sigma Chemical Co. (St.

Table 1. Systolic (SBP) and diastolic (DBP) blood pressure in normotensive (control, CT; uninephrectomized, UNR) and hypertensive (1K1C and DOCA-salt) awake and anesthetized rats.

\begin{tabular}{|c|c|c|c|}
\hline & \multirow{2}{*}{$\frac{\text { Awake rats }}{\mathrm{SBP}(\mathrm{mmHg})}$} & \multicolumn{2}{|c|}{ Anesthetized rats } \\
\hline & & $\mathrm{SBP}(\mathrm{mmHg})$ & $\mathrm{DBP}(\mathrm{mmHg})$ \\
\hline CT & $127 \pm 3.5$ & $101 \pm 1.8$ & $74 \pm 2.6$ \\
\hline UNR & $126 \pm 2.3$ & $98 \pm 1.8$ & $72 \pm 1.9$ \\
\hline $1 \mathrm{~K} 1 \mathrm{C}$ & $184 \pm 6.7^{+\#}$ & $104 \pm 3.5^{\# *}$ & $76 \pm 3.6^{\#}$ \\
\hline DOCA-salt & $141 \pm 6.5^{+}$ & $94 \pm 2.3^{+*}$ & $60 \pm 2.3^{+}$ \\
\hline
\end{tabular}

$+P<0.01$, comparison between hypertensive and normotensive rats; \#P<0.01, comparison between $1 \mathrm{~K} 1 \mathrm{C}$ and DOCA-salt rats;

$* \mathrm{P}<0.05$, comparison between hypertensive anesthetized and awake rats (t-test).

Figure 1. Time course of systolic blood pressure (SBP) changes during 1-h treatment with $18 \mu \mathrm{g} / \mathrm{kg}$ ouabain in normotensive (control, CT; uninephrectomized, UNR) and hypertensive (1K1C and DOCA-salt) rats after anesthesia. Points represent the means \pm SEM. $* \mathrm{P}<0.05$ compared to before ouabain treatment (time zero) for all groups (ANOVA).

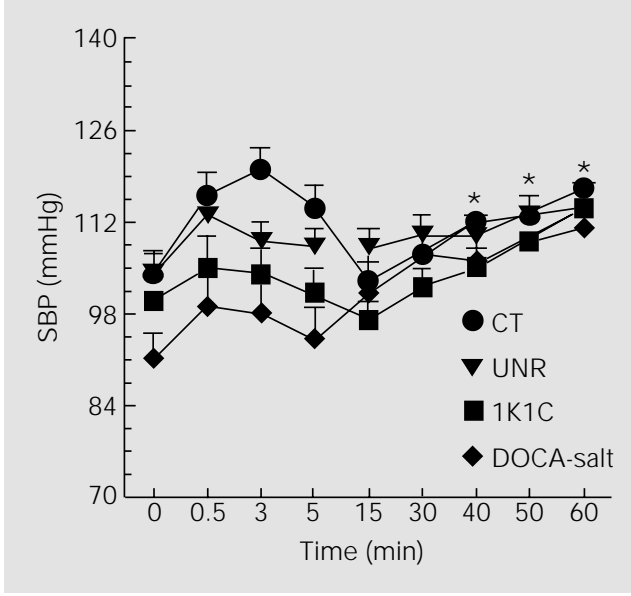

Louis, MO, USA). Heparin was purchased from Roche (São Paulo, SP, Brazil) and pentobarbital sodium was purchased from Fontoverter (Itapira, SP, Brazil).

\section{Results}

On the day before the experiments the systolic blood pressure was measured in awake unrestrained animals and the DOCAsalt and $1 \mathrm{~K} 1 \mathrm{C}$ hypertension was confirmed (Table 1). The systolic blood pressure measured after 30 days was higher in $1 \mathrm{~K} 1 \mathrm{C}$ than in DOCA-salt rats.

\section{Anesthetized animals}

After urethane anesthesia, systolic and diastolic blood pressure were reduced in all models and this reduction was significantly larger in the $1 \mathrm{~K} 1 \mathrm{C}$ and DOCA-salt groups (Table 1).

Figure 1 shows the time-course changes of systolic blood pressure for $1 \mathrm{~h}$ after $18 \mu \mathrm{g} /$ $\mathrm{kg}$ ouabain administration $(i v)$ in all groups. Between 1 to 3 min after injection, systolic blood pressure increased and then decreased back to control values (approximately 15 to $20 \mathrm{~min}$ ) after which it increased slowly again. It is interesting to note that this systolic blood pressure increment became significant only after $40 \mathrm{~min}$. Heart rate did not change after ouabain treatment and the changes produced by phenylephrine injections were similar both before and after ouabain (data not shown).

The administration of $18 \mu \mathrm{g} / \mathrm{kg}$ ouabain caused a similar increase in systolic blood pressure after $1 \mathrm{~h}$ in all groups studied (Figure 2). Diastolic blood pressure did not change significantly after this dose of ouabain in control rats but increased in the other groups, including uninephrectomized rats (Figure 3). Analysis of the changes in diastolic pressure before and $1 \mathrm{~h}$ after $18 \mu \mathrm{g} / \mathrm{kg}$ ouabain showed that hypertensive rats had a significant enhancement of diastolic pres- 

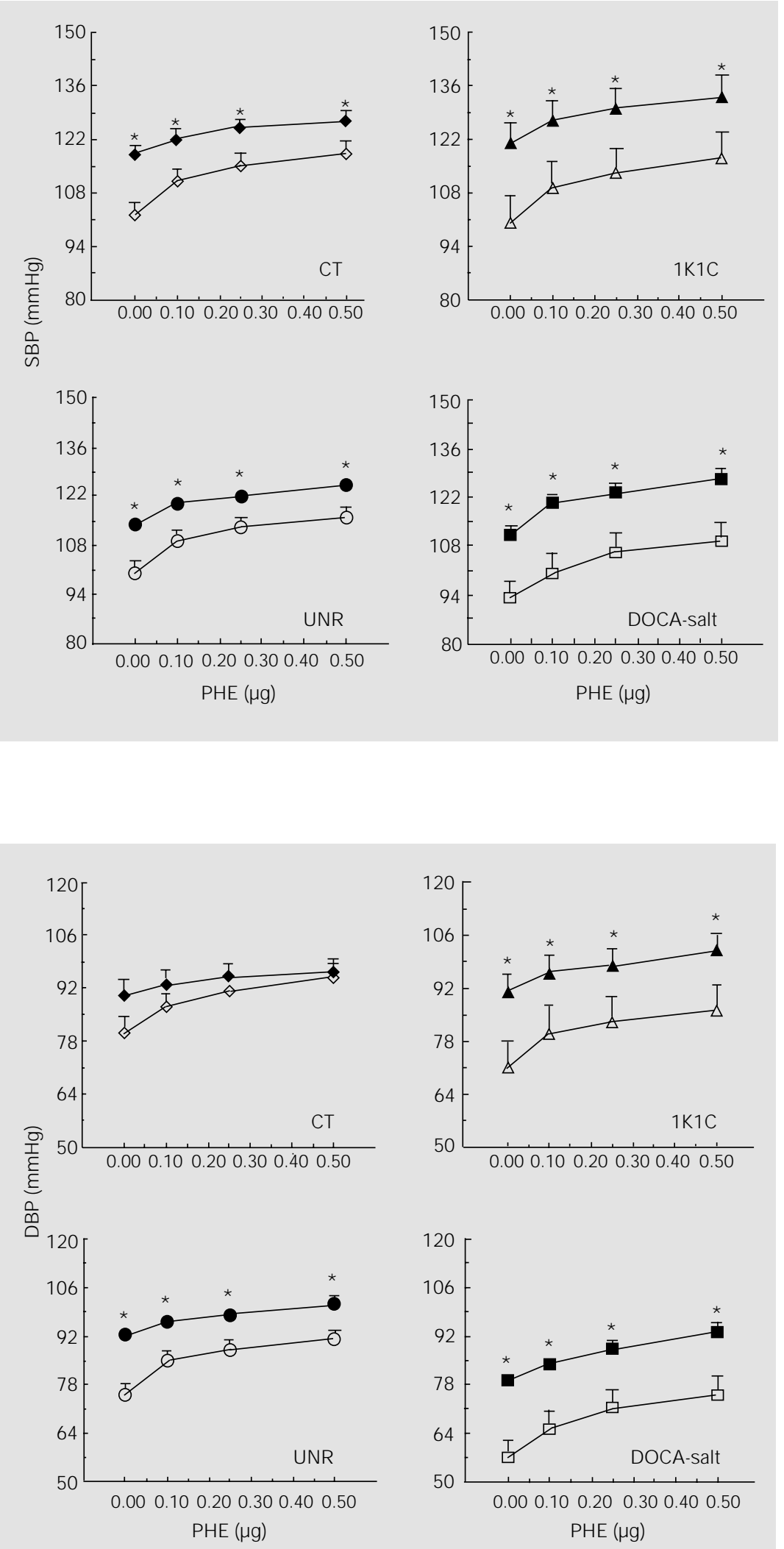

Figure 2. Changes in systolic blood pressure (SBP) in response to increasing doses of phenylephrine (PHE) in normotensive (control, CT; uninephrectomized, UNR) and hypertensive ( $1 \mathrm{~K} 1 \mathrm{C}$ and DOCA-salt) rats before (open symbols) and after (closed symbols) treatment with $18 \mu \mathrm{g} / \mathrm{kg}$ ouabain. Points represent the means \pm SEM. $* \mathrm{P}<0.05$ compared to before ouabain treatment (ANOVA).
Figure 3. Changes in diastolic blood pressure (DBP) in response to increasing doses of phenylephrine (PHE) in normotensive (control, CT; uninephrectomized, UNR) and hypertensive (1K1C and DOCA-salt) rats before (open symbols) and after (closed symbols) treatment with $18 \mu \mathrm{g} / \mathrm{kg}$ ouabain. Points represent the means \pm SEM. $* \mathrm{P}<0.05$ compared to before ouabain treatment (ANOVA). 


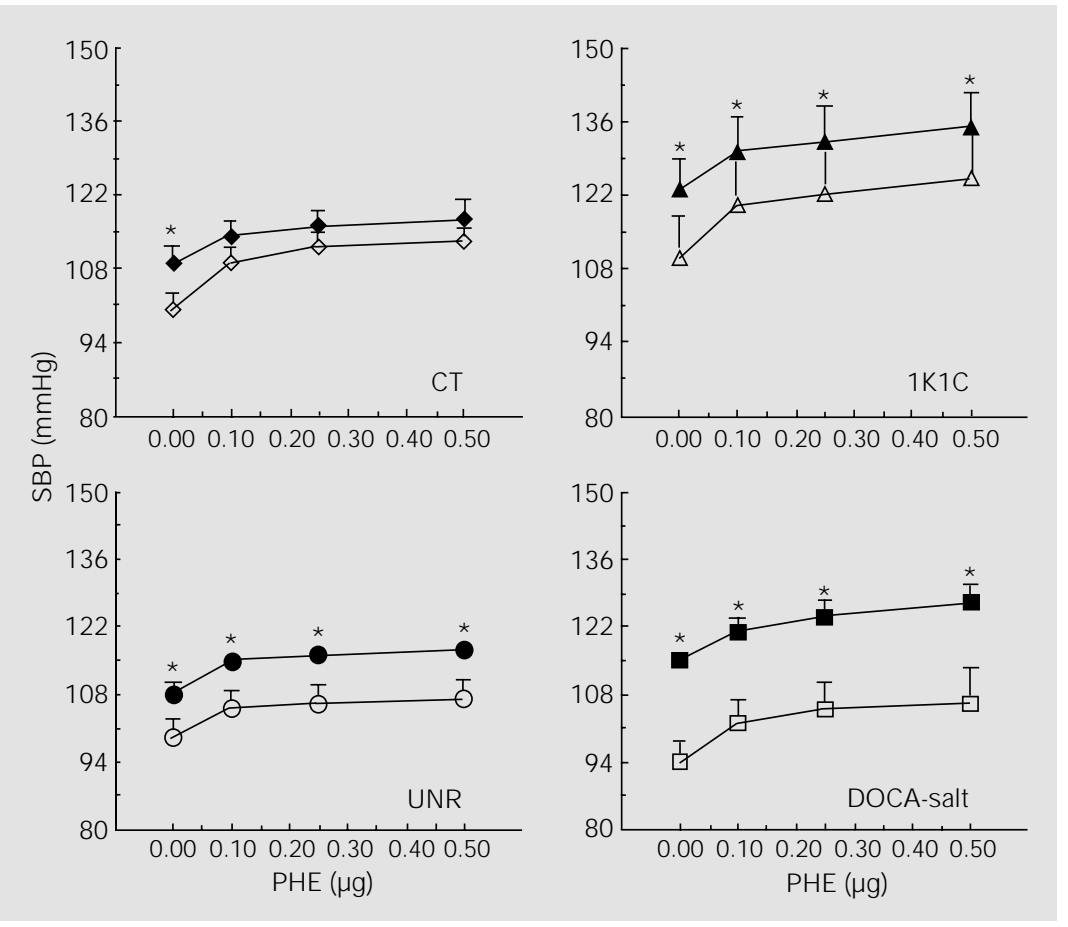

Figure 4. Changes in systolic blood pressure (SBP) in response to increasing doses of phenylephrine (PHE) in normotensive (control, CT; uninephrectomized, UNR) and hypertensive (1K1C and DOCA-salt) rats before (open symbols) and after (closed symbols) treatment with $0.18 \mu \mathrm{g} / \mathrm{kg}$ ouabain. Points represent the means $\pm \mathrm{SEM} . * \mathrm{P}<0.05$ compared to before ouabain treatment (ANOVA).
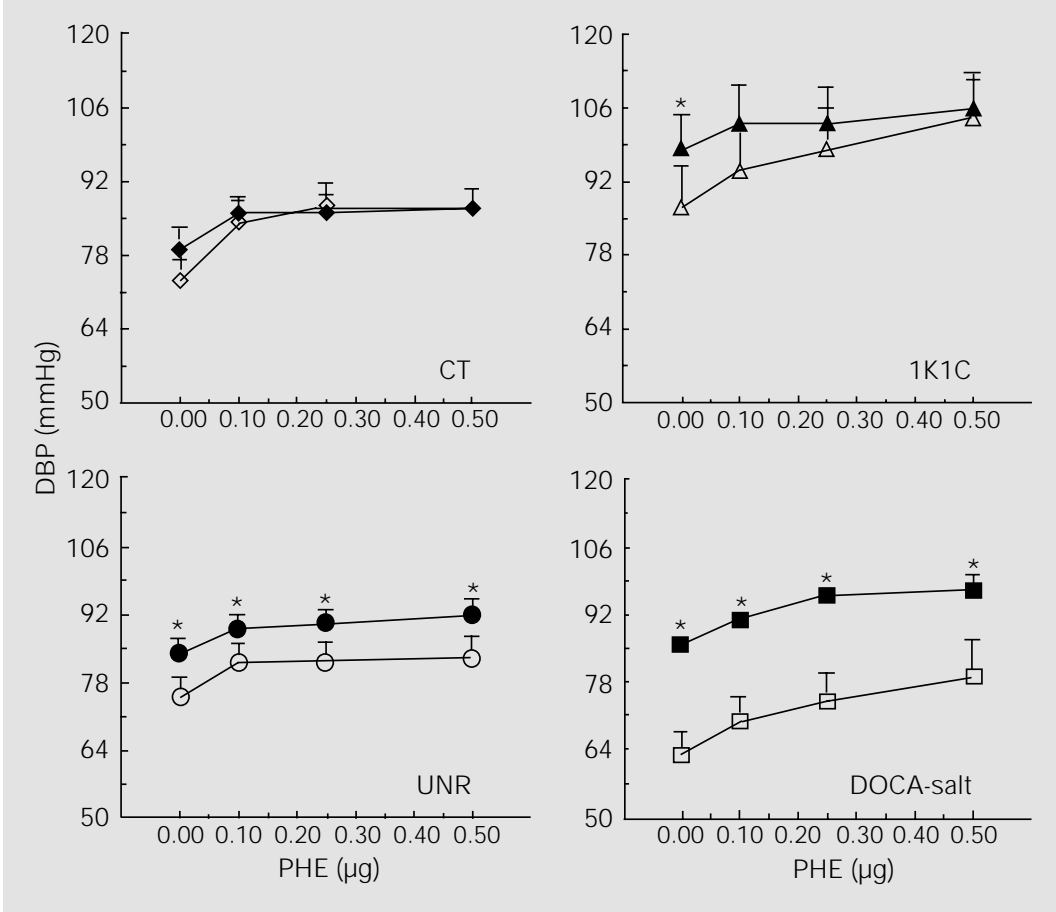

sure compared to the normotensive controls (normotensive - control: $8.50 \pm 2.62 \mathrm{mmHg}$; uninephrectomized: $16.41 \pm 3.47 \mathrm{mmHg}$, $\mathrm{P}>0.05$ vs control, $t$-test, and hypertensive $1 \mathrm{~K} 1 \mathrm{C}: 20.10 \pm 3.13 \mathrm{mmHg}, \mathrm{P}<0.02$ vs control, $t$-test; DOCA-salt: $21.71 \pm 4.20, \mathrm{P}<0.03$ $v s$ control, $t$-test). When pressor reactivity was tested (Figures 2 and 3 ), it could be seen that dose-dependent phenylephrine-evoked systolic and diastolic blood pressure responses were shifted upwards. However, ouabain did not change the gain of this response.

Treatment with $0.18 \mu \mathrm{g} / \mathrm{kg}$ ouabain produced a smaller but significant increment in systolic blood pressure and had no significant effect on diastolic blood pressure in the control rats (Figures 4 and 5). This dose is expected to produce nanomolar levels of circulating ouabain if we assume that the drug is being diluted in $40 \mathrm{ml}$ of extracellular fluid per each $100 \mathrm{~g}$ of rat. In normotensive rats, phenylephrine-evoked pressor effects were similar before and after ouabain treatment. However, this very low dose of ouabain increased both systolic and diastolic blood pressure in the hypertensive groups (1K1C and DOCA-salt), and in the uninephrectomized rats (Figures 4 and 5). When pressor reactivity was tested (Figures 4 and 5) it could be seen that dose-dependent phenylephrine-evoked systolic and diastolic blood pressure responses were shifted upwards. Moreover, analysis of the magnitude of systolic and diastolic pressure increment before and $1 \mathrm{~h}$ after $0.18 \mu \mathrm{g} / \mathrm{kg}$ ouabain showed that DOCA-salt rats were more responsive to the effects of ouabain than normotensive and $1 \mathrm{~K} 1 \mathrm{C}$ hypertensive rats (Table 2).

Figure 5. Changes in diastolic blood pressure (DBP) in response to increasing doses of phenylephrine (PHE) in normotensive (control, CT; uninephrectomized, UNR) and hypertensive (1K1C and DOCA-salt) rats before (open symbols) and after (closed symbols) treatment with $0.18 \mu \mathrm{g} / \mathrm{kg}$ ouabain. Points represent the means \pm SEM. $* \mathrm{P}<0.05$ compared to before ouabain treatment (ANOVA). 
Another dose of ouabain was used. Since we knew from previous experiments that SHR are more resistant to toxic doses of ouabain, another protocol was performed using $1.8 \mathrm{mg} / \mathrm{kg}$ ouabain to test this behavior in another hypertensive group. $1 \mathrm{~K} 1 \mathrm{C}$ rats and their uninephrectomized controls were investigated and both behaved like SHR, with an increase in systolic and diastolic blood pressure after ouabain treatment (Table $3)$.

\section{Isolated rat tail vascular bed preparation}

Phenylephrine produced a dose-dependent increase in mean perfusion pressure in the rat tail vascular bed from all animals (Figure 6). This increment did not differ between normotensive and $1 \mathrm{~K} 1 \mathrm{C}$ hypertensive rats but was smaller in DOCA-salt rats compared to the other groups (Figure 6).

After treatment with $10 \mathrm{nM}$ ouabain for $60 \mathrm{~min}$, the baseline perfusion pressure was reduced in all animals (normotensive: control, from $74 \pm 3.24$ to $66 \pm 1.60 \mathrm{mmHg}$, and uninephrectomized, from $79 \pm 4.88$ to $64 \pm$ $3.13 \mathrm{mmHg}$; hypertensive: $1 \mathrm{~K} 1 \mathrm{C}$, from $82 \pm$ 6.85 to $67 \pm 2.12 \mathrm{mmHg}$, and DOCA-salt, from $77 \pm 6.13$ to $61 \pm 4.93 \mathrm{mmHg} ; \mathrm{P}<0.05$ for all groups, paired $t$-test). Perfusion with ouabain-free Krebs solution for $1 \mathrm{~h}$ also reduced the baseline perfusion pressure but did not enhance the pressor response to phenylephrine (data not shown). After ouabain treatment the pressor response to phenylephrine was significantly enhanced only at the 5- and 10- $\mu$ g doses in normotensive and $1 \mathrm{~K} 1 \mathrm{C}$ hypertensive rats (Figure 6). However, in DOCA-salt hypertensive rats the increment of the pressor response obtained after ouabain treatment became significant at a lower dose of phenylephrine, i.e., $1 \mu \mathrm{g}$ (Figure 6).

Table 2. Changes in systolic (SBP) and diastolic (DBP) blood pressure before and after $0.18 \mu \mathrm{g} / \mathrm{kg}$ ouabain in normotensive (control, CT; uninephrectomized, UNR) and hypertensive (IKIC and DOCA-salt) rats.

\begin{tabular}{lcc}
\hline & $\Delta \mathrm{SBP}(\mathrm{mmHg})$ & $\Delta \mathrm{DBP}(\mathrm{mmHg})$ \\
\hline CT & $7.6 \pm 3.6$ & $3.7 \pm 3.6$ \\
UNR & $9.3 \pm 2.7$ & $9.2 \pm 3.1$ \\
1K1C & $12.7 \pm 4.2$ & $10.7 \pm 3.8$ \\
DOCA-salt & $24.3 \pm 2.6^{*+}$ & $27.2 \pm 3.5^{*+}$
\end{tabular}

$* \mathrm{P}<0.001$, comparison between hypertensive and normotensive rats;

$+P<0.001$, comparison between DOCA-salt and $1 \mathrm{~K} 1 \mathrm{C}$ rats (t-test).

Table 3. Changes in systolic (SBP) and diastolic (DBP) arterial blood pressure (in $\mathrm{mmHg}$ ) in response to the vasopressor effects of increasing doses of phenylephrine (PHE) before and after $1.8 \mathrm{mg} / \mathrm{kg}$ ouabain treatment in normotensive (control, CT; uninephrectomized, UNR) and hypertensive (1K1C) rats.

\begin{tabular}{|c|c|c|c|c|c|c|c|c|c|}
\hline & & \multicolumn{2}{|c|}{ PHE (0) } & \multicolumn{2}{|c|}{ PHE $(0.1 \mu \mathrm{g})$} & \multicolumn{2}{|c|}{ PHE $(0.25 \mu \mathrm{g})$} & \multicolumn{2}{|c|}{ PHE $(0.5 \mu \mathrm{g})$} \\
\hline & & SBP & DBP & SBP & DBP & SBP & DBP & SBP & DBP \\
\hline \multirow[t]{2}{*}{ CT } & Before & $109 \pm 9.4$ & $79 \pm 10.6$ & $120 \pm 9.4$ & $90 \pm 10.4$ & $120 \pm 6.9$ & $93 \pm 8.1$ & $124 \pm 6.7$ & $98 \pm 7.9$ \\
\hline & After & $88 \pm 4.4^{*}$ & $78 \pm 6.1$ & $98 \pm 7.7^{*}$ & $85 \pm 5.9$ & $102 \pm 10.5^{*}$ & $87 \pm 7.2$ & $100 \pm 10.2^{*}$ & $90 \pm 7.6$ \\
\hline \multirow[t]{2}{*}{ UNR } & Before & $99 \pm 4.9$ & $72 \pm 5.3$ & $104 \pm 4.5$ & $78 \pm 4.6$ & $107 \pm 3.9$ & $81 \pm 4.6$ & $110 \pm 3.7$ & $85 \pm 4.6$ \\
\hline & After & $114 \pm 5.3^{*}$ & $93 \pm 5.3^{*}$ & $119 \pm 5.2^{*}$ & $97 \pm 5.1^{*}$ & $120 \pm 4.7^{*}$ & $97 \pm 5.2^{*}$ & $123 \pm 5.1^{*}$ & $102 \pm 5.2^{*}$ \\
\hline \multirow[t]{2}{*}{$1 \mathrm{~K} 1 \mathrm{C}$} & Before & $112 \pm 6.1$ & $81 \pm 5.9$ & $121 \pm 6.4$ & $92 \pm 6.5$ & $123 \pm 6.5$ & $94 \pm 6.3$ & $127 \pm 6.5$ & $98 \pm 6.3$ \\
\hline & After & $141 \pm 7.7^{*}$ & $116 \pm 7.8^{*}$ & $145 \pm 7.6^{*}$ & $118 \pm 7.6^{*}$ & $147 \pm 7.8^{*}$ & $120 \pm 7.8^{*}$ & $150 \pm 8.0^{*}$ & $123 \pm 8.0^{*}$ \\
\hline
\end{tabular}

*P $<0.05$ compared to before ouabain treatment (ANOVA). 
Figure 6. Changes in mean perfusion pressure (MPP) in response to increasing doses of phenylephrine (PHE) in normotensive (control, CT; uninephrectomized, UNR) and hypertensive (1K1C and DOCA-salt) rats before (open symbols) and after (closed symbols) infusion of 10 nM ouabain. Points represent means \pm SEM. ${ }^{*} \mathrm{P}<0.05$ compared to before ouabain treatment; ${ }^{+} \mathrm{P}<0.05$ compared to normotensive control, uninephrectomized and hypertensive $1 \mathrm{~K} 1 \mathrm{C}$ rats rats (ANOVA).

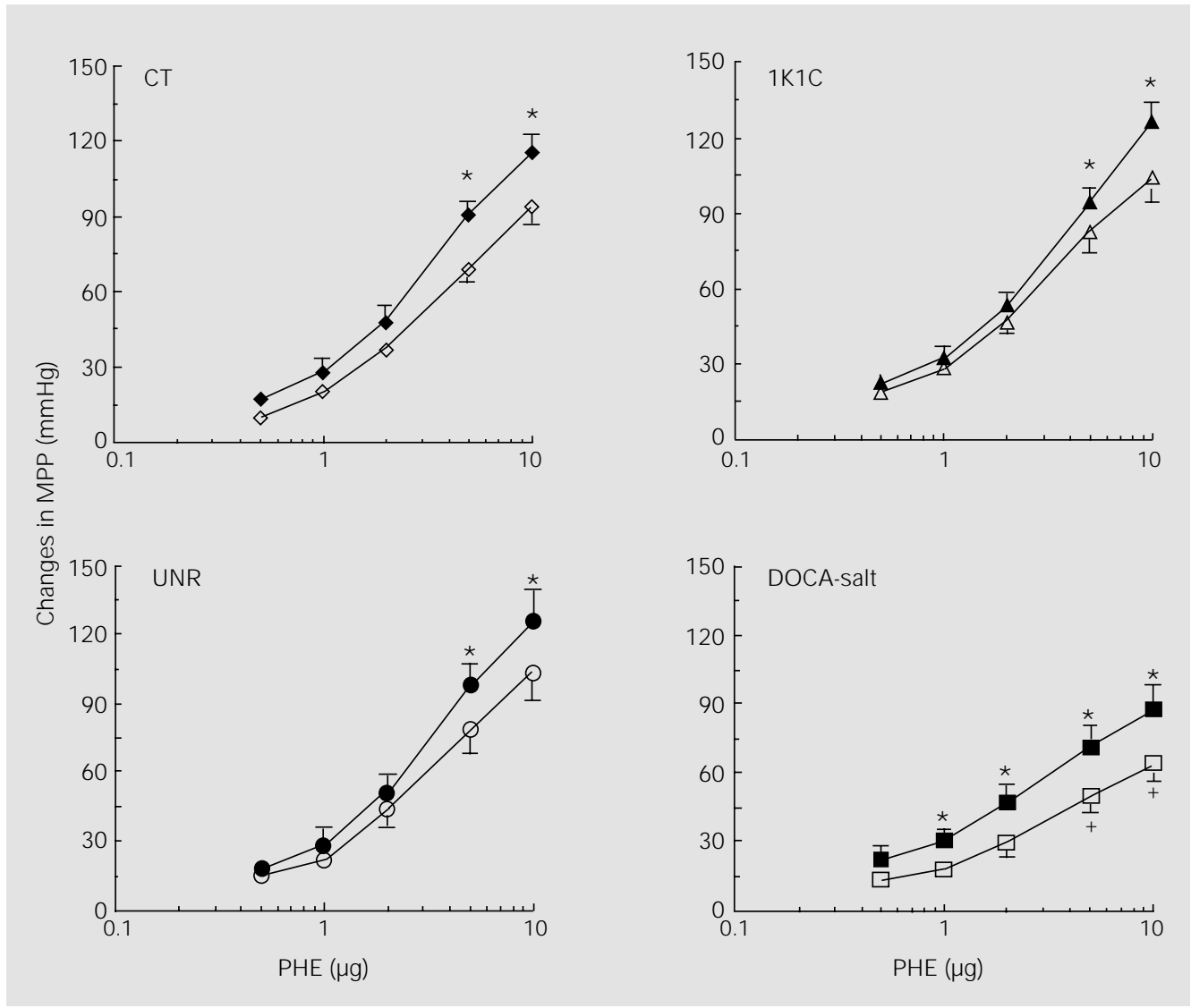

\section{Discussion}

The present results suggest that DOCAsalt rats were more sensitive to pressor effects after treatment with small doses of ouabain $(0.18 \mu \mathrm{g} / \mathrm{kg})$ than normotensive and $1 \mathrm{~K} 1 \mathrm{C}$ rats in vivo. When using higher doses of ouabain $(18 \mu \mathrm{g} / \mathrm{kg})$ the hypertensive $1 \mathrm{~K} 1 \mathrm{C}$ and DOCA-salt rats showed similar behavior regarding the pressor effects induced by this digitalis compound. Although ouabain did not increase sensitivity to phenylephrine in vivo, this effect was observed in vitro in isolated vessels obtained from DOCA-salt rats. These findings suggest that the increase of arterial pressure caused by small doses of ouabain in DOCA-salt rats seems to be the result of an increased sensitization of vascular smooth muscle to pressor $\alpha$-agonist agents. Our results also suggest that the pres- sor response to ouabain depends on the dose and on the hypertensive animal model used.

Ouabain inhibits $\mathrm{Na}^{+}, \mathrm{K}^{+}$-ATPase by binding to the $\alpha$ subunits of the enzyme in several tissues like the heart, vessels, kidneys and the nervous system $(3,6,11)$. The cell membrane enzyme $\mathrm{Na}^{+}, \mathrm{K}^{+}$-ATPase is the biochemical expression of the electrogenic $\mathrm{Na}^{+}$ pump and exchanges $3 \mathrm{Na}^{+}$for $2 \mathrm{~K}^{+}$, maintaining the resting potential of excitable cells (3). A reduction in $\mathrm{Na}^{+}$pump activity leads to $\mathrm{Na}^{+}$accumulation in the myoplasm (4). Inhibition of the pump also affects the $\mathrm{Na}^{+} /$ $\mathrm{Ca}^{2+}$ exchange mechanism and, consequently, the amount of activator $\mathrm{Ca}^{2+}$ necessary for contraction in several tissues such as vascular smooth muscle (4). By inhibiting the $\mathrm{Na}^{+}$pump, ouabain may have effects on the homeostatic mechanisms affecting the regulatory control of blood pressure, there- 
fore playing a central role in the development and maintenance of hypertension (4). Indeed, many reports have suggested such a role since ouabain can produce hypertension during long-term administration in rats $(9,12,13)$.

Recently, ouabain has been reported to be an adrenocortical hormone present in plasma at nanomolar or subnanomolar concentrations $(4,8,9)$. There are results indicating that a circulating ouabain-like substance is increased in DOCA-salt rats and in lowrenin rat models such as $1 \mathrm{~K} 1 \mathrm{C}(14,15)$. A recent study using anesthetized normotensive and SHR rats has reported that the pressor effects induced by ouabain were operative in vivo (1). In SHR, sensitization was present at doses of ouabain reaching the nanomolar level. This effect was observed when vascular smooth muscle was challenged by phenylephrine stimulation after ouabain treatment. Therefore, the possibility of sensitization by ouabain may manifest in vivo since vascular smooth muscle is continuously stimulated by the sympathetic drive or by the presence of endogenous vasopressor substances. The present study was designed to investigate the vascular reactivity of anesthetized $1 \mathrm{~K} 1 \mathrm{C}$ and DOCA-salt rats after several ouabain treatments.

As seen in Table 3, a toxic dose of ouabain $(1.8 \mathrm{mg} / \mathrm{kg})$ produced a hypotensive effect in normotensive rats but not in the other groups. It has been reported that normotensive rats show a reduction of systolic blood pressure after this ouabain treatment while SHR show an increase in systolic blood pressure (1). Diastolic blood pressure did not change significantly after $1.8 \mathrm{mg} / \mathrm{kg}$ ouabain treatment in normotensive rats but increased in the others. Also, confirming previous findings (1), this large dose of ouabain frequently produced arrhythmias in normotensive rats, characterizing a toxic effect. The hypotension was probably caused by a reduction in cardiac output produced by the presence of arrhythmias in the normotensive group or by a putative calcium overload causing diastolic dysfunction. This suggests that hypertensive and uninephrectomized rats are more resistant to the toxic effects of ouabain than normotensive rats.

The arrhythmogenic effect of ouabain is also related to the inhibition of $\mathrm{Na}^{+}, \mathrm{K}^{+}-$ ATPase. This inhibition increases intracellular sodium concentration and depolarizes the cell. The $\mathrm{Na}^{+} / \mathrm{Ca}^{2+}$ exchange activity is also reduced and $\mathrm{Ca}^{2+}$ accumulates inside the cell. Once intracellular $\mathrm{Ca}^{2+}$ increases, the $\mathrm{Na}^{+} / \mathrm{Ca}^{2+}$ exchanger is stimulated and, since this is an electrogenic exchange, depolarizing currents are generated causing arrhythmias (16). The resistance to the toxic effects of ouabain in the hypertensive group has been explained by the fact that $\mathrm{Na}^{+}, \mathrm{K}^{+}-$ ATPase activity is reduced in hypertrophic hearts from hypertensive animals $(17,18)$. Moreover, some of these reports show that the $\alpha_{2}$ isoform of $\mathrm{Na}^{+}, \mathrm{K}^{+}$-ATPase is reduced (18) while the $\alpha_{3}$ isoform increases (19). Since the $\alpha_{3}$ isoform is less sensitive to intracellular $\mathrm{Na}^{+}$(19), this could explain the increased resistance of the hypertrophied myocardium to the effects of this digitalis compound.

The intermediate dose of ouabain $(18 \mu \mathrm{g} /$ $\mathrm{kg}$ ) increased arterial systolic blood pressure after $1 \mathrm{~h}$. It is interesting to note that ouabain, even at the largest dose, never increased significantly the diastolic blood pressure of normotensive rats, which reflects the lack of effects on systemic peripheral resistance. However, a significant diastolic blood pressure increment was observed after all ouabain treatments in other groups. It should be emphasized that, although we did not observe differences among groups, when the changes in systolic pressure were evaluated after $18 \mu \mathrm{g} / \mathrm{kg}$ ouabain, this dose was able to increase diastolic pressure in hypertensive animals when compared to normotensive animals. This result was similar to what was reported before for SHR (1), indicating that the effect of ouabain on arterial blood pres- 
sure is larger in these animals. Ouabain treatment with the smaller dose of $0.18 \mu \mathrm{g} / \mathrm{kg}$ was able to increase arterial pressure. However, in contrast to what occurred when 18 $\mu \mathrm{g} / \mathrm{kg}$ ouabain was used, this pressure increment was larger in DOCA-salt rats than in normotensive and $1 \mathrm{~K} 1 \mathrm{C}$ rats. These data show that not all hypertension models have the same sensitivity to ouabain at very small doses. Treatment with ouabain increased arterial pressure and shifted upwards the vasopressor responses to phenylephrine in all models at all doses studied. However, no changes in the gain of phenylephrine pressor responses were observed. An interesting result was obtained with the uninephrectomized rats whose response to ouabain reached an intermediate level between hypertensive and normotensive control rats. This was not the only difference they showed compared to normal rats, since a reduction of cardiac contractility was also reported following uninephrectomy (20). These findings led us to conclude that uninephrectomized animals cannot be considered as a normal control. Our results, however, cannot discriminate the underlying mechanisms responsible for this sensitization effect but suggest that a) ouabain increases blood pressure and maintains phenylephrine-evoked pressor responses in all groups studied when acute digitalization doses are used, b) these effects are still present even when smaller doses of ouabain are used in all groups of rats except the normotensive ones, c) the increment in systolic and diastolic blood pressure is more efficient in DOCA-salt hypertensive rats, and d) hypertensive and uninephrectomized rats are less sensitive to toxic doses of ouabain.

One possible mechanism that explains the changes in pressor responses caused by ouabain in these models of hypertension is a vascular mechanism. Previous reports have demonstrated that higher doses of ouabain sensitize the contractile response to $\alpha$-adrenergic agonists and to $\mathrm{KCl}$ in $1 \mathrm{~K} 1 \mathrm{C}$ rats
$(21,22)$. The same occurs with DOCA-salt rats in which ouabain treatment increased even more the pressor responses (23). This would help to explain why $18 \mu \mathrm{g} / \mathrm{kg}$ ouabain was capable to produce a significant increase of diastolic pressure in hypertensive, but not normotensive rats. However, these results were obtained with higher doses of ouabain and this may mask a different effect obtained with lower doses of ouabain. Indeed, the effect obtained in DOCA-salt rats after 0.18 $\mu \mathrm{g} / \mathrm{kg}$ ouabain could be explained by such enhanced sensitization of the vascular bed.

It has been reported that low plasma concentrations of ouabain may modulate vascular reactivity without directly affecting vascular smooth muscle tone $(2,24,25)$. For example, low ouabain concentrations $(10 \mathrm{nM})$ increase caffeine-evoked contractions in rat aortic rings (26). Using a perfused rat tail vascular bed preparation we showed $(2,24)$ that $10 \mathrm{nM}$ ouabain did not alter baseline perfusion pressure but increased the sensitivity to phenylephrine-evoked pressor responses both in normotensive rats and SHR. The same was observed in our normotensive control rats. Ouabain was able to sensitize the pressor response to phenylephrine in the tail vascular bed from all models studied, without causing changes in baseline perfusion pressure.

Recently, it has been shown that small increments of myoplasmic $\mathrm{Ca}^{2+}$ may increase vascular reactivity because of the amplifier action of the sarcoplasmic reticulum $(4,5)$. Thus, low concentrations of ouabain can augment $\mathrm{Ca}^{2+}$ transients in vascular smooth muscle without increasing cytosolic sodium (25). This mechanism explains why low concentrations of ouabain increase the contractile response to phenylephrine without causing contraction by a direct action on vascular smooth muscle. However, by comparing the sensitization of the phenylephrine pressor response among the studied models it was possible to see that in vitro treatment with 10 $\mathrm{nM}$ ouabain is more effective in DOCA-salt 
rats when compared with normotensive and hypertensive $1 \mathrm{~K} 1 \mathrm{C}$ rats. This result also explains why low doses of ouabain caused a larger pressor response in DOCA-salt rats compared to $1 \mathrm{~K} 1 \mathrm{C}$. Possible mechanisms that could be modified in these models of hypertension and could explain the results described here are changes in the expression and activity of the $\mathrm{Na}^{+}$pump.

The expression and activity of $\mathrm{Na}^{+}, \mathrm{K}^{+}-$ ATPase and its $\alpha$ isoform are regulated by multiple factors such as developmental stage (27), hormones (28), endothelial factors (29) and the occurrence of hypertension $(30,31)$. Furthermore, it has been shown that $\alpha$ subunits of $\mathrm{Na}^{+}, \mathrm{K}^{+}$-ATPase consist of different $\alpha_{1}, \alpha_{2}$ and $\alpha_{3}$ subunits with different affinities for digitalis (11). Since the $\mathrm{Na}^{+}, \mathrm{K}^{+}-$ ATPase isoforms may change under several situations the maintenance of the sensitizing mechanism could be of clinical relevance. Recently, Blaustein et al. (5) suggested that a special distribution of the $\alpha_{2}$ and $\alpha_{3}$ isoforms of $\mathrm{Na}^{+}, \mathrm{K}^{+}$-ATPase exists in the sarcolemma that binds ouabain preferentially and they are located near the vesicles of the sarcoplasmic reticulum. This special localization enables the increment of cytosolic calcium near the reuptake sites, facilitating the operation of the proposed mechanism. Then, when vascular smooth muscle is stimulated the final result is an "amplification" of the calcium released and an increase in the response of the vasculature to agents that produce constriction $(1,2,24,26)$. This is an amplification mechanism that operates even at low ouabain concentrations.

These results lead us to speculate that there might be differences in $\mathrm{Na}^{+}, \mathrm{K}^{+}$-ATPase isoforms in these normotensive and hypertensive rats. One possible explanation for this difference would be the up-regulation in hypertensive groups. Recently, Liu et al. (31) reported up-regulation of both $\alpha_{1}$ and $\alpha_{2}$ isoforms after a 2- or 4-day stretch in cultured vascular smooth muscle cells. Similar results have been obtained in several models of cardiac hypertrophy $(18,19,32)$. Increase of $\mathrm{Na}^{+}$pump activity and up-regulation of the expression of $\alpha_{1}$ mRNA in the heart, together with a down-regulation of the $\alpha_{2}$ mRNA as a result of DOCA-salt hypertension, has been reported $(6,30)$. However, increased $\alpha_{1}$ isoform activity would result in low levels of inhibition by ouabain sufficient to make $1 \mathrm{~K} 1 \mathrm{C}$ and uninephrectomized rats more resistant to the toxic effects of the drug. In the aorta, it has been reported that corticosteroids regulate $\mathrm{Na}^{+}, \mathrm{K}^{+}$-ATPase isoform expression and activity in vascular tissue, suggesting a mineralocorticoid-dependent modulation of the $\alpha_{2}$ isoform (28). Also, up-regulation of the $\alpha_{2}$ isoform in DOCA-salt hypertensive rats may facilitate ouabain binding, further increasing its sensitizing effects.

The ability of ouabain to elevate arterial pressure in anesthetized rats might be the result of a peripheral and central pathway. Ouabain is reported to activate the sympathetic autonomic nervous system and to reduce the efficiency of the baroreflex, which in turn, contributes to an increase in arterial pressure (33). In addition, hypertension has been reported to occur with enhanced sympathetic activity and a blunted baroreflex in $1 \mathrm{~K} 1 \mathrm{C}$ and DOCA-salt rats $(34,35)$. Thus, a putative effect of ouabain potentiating this mechanism cannot be ruled out. Another important finding supported by our results is the fact that ouabain directly enhances the release of norepinephrine from nerve terminals (36). Moreover, greater vascular reactivity to vasopressor agents, increased endothelin levels and an increased activity of the renin-angiotensin system have been reported to occur in both $1 \mathrm{~K} 1 \mathrm{C}$ and DOCA-salt rats $(37,38)$. Thus, sensitization of the vascular smooth muscle by ouabain, associated with the greater release of norepinephrine by nerve terminals, might explain the increase of diastolic pressure produced by ouabain. Although ouabain sensitizes the vessels to the pressor effect of phenylephrine in vitro, this action did not occur in vivo. In vivo, the 
pressor effects of phenylephrine were displaced upwards but no sensitization was observed. Part of this response can be explained by the action of ouabain or by the arterial pressure elevation stimulating the baroreflex. Also, there are reports showing that ouabain, instead of blunting the baroreflex, can enhance it in normotensive animals, an effect that is amplified in SHR (39). On this basis, we may suppose that a putative in vivo sensitization might be masked by this effect.

Another interesting aspect is related to the fact that the in vitro pressor responses to phenylephrine are reduced in DOCA-salt rats compared to the other models studied. Previous reports have shown that in DOCAsalt rats the chronic increment of sympathetic tone in vascular beds with more sympathetic innervation, like the mesenteric arteries, might reduce the response of these arteries to norepinephrine. Prolonged exposure to high levels of norepinephrine may reduce the action of $\alpha$-adrenergic agonists via stimulation of the vascular endothelium, leading to an increased production of vasodilator factors like nitric oxide (40). This mechanism should explain the reduction of the pressor response to phenylephrine of the tail vascular bed from DOCA-salt rats since the tail artery is highly innervated. In addition, previous results from our laboratory have suggested that endothelial modulation of the pressor response to phenylephrine is enhanced in DOCA-salt rats.

In conclusion, these results suggest that ouabain treatment increases blood pressure and that this increment is more marked in hypertensive rats. The pressor effects after the administration of low ouabain concentrations were more pronounced in hypertensive DOCA-salt rats in vivo and in vitro. These increments still occurred with very low doses of ouabain in hypertensive rats, suggesting an enhanced pressor reactivity which may contribute to the genesis and maintenance of hypertension.

\section{References}

1. Vassallo DV, Songu-Mize E, Rossoni LV \& Amaral SMC (1997). Effects of ouabain on vascular reactivity. Brazilian J ournal of Medical and Biological Research, 30: 545552.

2. Rossoni LV, Cunha V, França A \& Vassallo DV (1999). The influence of nanomolar ouabain on vascular pressor responses is modulated by the endothelium. J ournal of Cardiovascular Pharmacology, 34: 887892.

3. Lingrel J B (1992). Na,K-ATPase: isoform structure, function, and expression. J ournal of Bioenergetics and Biomembranes, 24: 263-270.

4. Blaustein MP (1996). Endogenous ouabain: Role in the pathogenesis of hypertension. Kidney International, 49: 17481753.

5. Blaustein MP, J uhaszova $M \&$ Golovina VA (1998). The cellular mechanism of action of cardiotonic steroids: A new hypothesis. Clinical and Experimental Hypertension, 20: 691-703.

6. Sahin-Erdemli I, Medford RM \& SonguMize E (1995). Regulation of $\mathrm{Na}^{+}, \mathrm{K}^{+}-$ ATPase $\alpha$-subunit isoforms in rat tissues during hypertension. European J ournal of Pharmacology, 292: 163-171.

7. Rossi GP, Manunta P, Hamlyn J M, Pavan E, De Tone R, Semplicini A \& Pessina AC (1995). Immunoreactive endogenous ouabain in primary aldosteronism and essential hypertension: relationship with plasma renin, aldosterone and blood pressure levels. J ournal of Hypertension, 13: 11811191.

8. Ludens JH, Clark MA, Robinson FG \& DuCharme DW (1992). Rat adrenal cortex is a source of a circulating ouabain-like compound. Hypertension, 19: 721-724.

9. Manunta $P$, Rogowski AC, Hamilton BP \& Hamlyn J M (1994). Ouabain-induced hypertension in the rat: relationships among circulating and tissue ouabain and blood pressure. J ournal of Hypertension, 12: 549-560.

10. França AS, Rossoni LV, Amaral SMC \& Vassallo DV (1997). Reactivity of the isolated perfused rat tail vascular bed. Brazilian J ournal of Medical and Biological Research, 30: 891-895.

11. Sweadner KJ (1989). Isozymes of the $\mathrm{Na}^{+} /$ $\mathrm{K}^{+}$-ATPase. Biochimica et Biophysica
Acta, 988: 185-220.

12. Yuan CM, Manunta P, Hamlyn J M, Chen S, Bohen E, Yeun J , Haddy FJ \& Pamnani MB (1993). Long-term ouabain administration produces hypertension in rats. Hypertension, 22: 178-187.

13. Rossoni LV, Lores A, Salaices $M$ \& Vassallo DV (2000). Alterations on vascular reactivity and $\mathrm{Na}^{+} \mathrm{K}^{+}$-ATPase in hypertension induced by chronic administration of ouabain. Annals of the XVI Latin-American Congress of Pharmacology, São Paulo, SP, Brazil, September 13-17, No. 02.021, 124.

14. Kojima I (1984). Circulating digitalis-like substance is increased in DOCA-salt hypertension. Biochemical and Biophysical Research Communications, 122: 129-136.

15. Pamnani MB \& Haddy FJ (1988). Humoral sodium-potassium inhibitor in reduced renal mass-saline hypertension rats. Progress in Biochemical Pharmacology, 23: 3545.

16. Nordin C (1989). Abnormal $\mathrm{Ca}^{2+}$ handling and the generation of ventricular arrhythmias in congestive heart failure. Heart Failure, 5: 143-154. 
17. Sweadner $\mathrm{KJ}$, Herrera $\mathrm{VL}$, Amato $\mathrm{S}$, Moellmann A, Gibbons DK \& Repke KR (1994). Immunologic identification of $\mathrm{Na}+$, $\mathrm{K}(+)$-ATPase isoforms in myocardium. Isoform change in deoxycorticosterone acetate-salt hypertension. Circulation Research, 74: 669-678.

18. Liu X \& Songu-Mize E (1997). Alterations in alpha subunit expression of cardiac $\mathrm{Na}^{+}, \mathrm{K}^{+}$-ATPase in spontaneously hypertensive rats: effect of antihypertensive therapy. European J ournal of Pharmacology, 327: 151-156.

19. Charlemagne $D \&$ Swynghedauw $B$ (1995). Myocardial phenotypic changes in $\mathrm{Na}^{+}$, $\mathrm{K}^{+}$ATPase in left ventricular hypertrophy: pharmacological consequences. European Heart J ournal, 16 (Suppl C): 20-23.

20. Vassallo DV, Vasquez EC \& Mill J G (1990). Myocardial depression produced by unilateral nephrectomy in rats. Clinical and Experimental Hypertension. Part A, Theory and Practice, A12: 597-616.

21. Ceron PIB \& Bendhack LM (1997). Increased contractile response induced with ouabain is abolished by thapsigargin in aorta of renal hypertensive rats. General Pharmacology, 29: 707-712.

22. Overbeck HW (1984). Effect of ouabain on arteriolar responses to norepinephrine in chronic, benign, volume-expanded hypertension. Hypertension, 6 (Suppl I): 8297.

23. Sekihara H, Yazaki Y \& Kojima T (1992). Ouabain as an amplifier of mineralocorticoid-induced hypertension. Endocrinology, 131: 3077-3082.

24. Davel APC, Rossoni LV \& Vassallo DV (2000). Effects of ouabain on the pressor response to phenylephrine and on the sodium pump activity in diabetic rats. European J ournal of Pharmacology, 406: 419427.
25. Arnon A, Hamlyn JM \& Blaustein $M P$ (2000). Ouabain augments $\mathrm{Ca}^{2+}$ transients in arterial smooth muscle without rising cytosolic $\mathrm{Na}^{+}$. American J ournal of Physiology, 279: H679-H691.

26. Weiss DN, Podberesky DJ, Heidrich J \& Blaustein MP (1994). Nanomolar ouabain augments caffeine-evoked contractions in rat arteries. American J ournal of Physiology, 265: C1443-C1448.

27. Orlowski J \& Lingrel J B (1988). Tissuespecific and developmental regulation of rat $\mathrm{Na}^{+}, \mathrm{K}^{+}-\mathrm{ATP}$ ase catalytic $\alpha$ isoform and B subunit mRNAs. J ournal of Biological Chemistry, 263: 10436-10442.

28. Michea L, Valenzuela V, Bravo I, Schuster A \& Marusic ET (1998). Adrenal-dependent modulation of the catalytic subunit isoforms of the $\mathrm{Na}^{+}-\mathrm{K}^{+}-$ATPase in aorta. American J ournal of Physiology, 275: E1072-E1081.

29. Gupta S, Phipps K \& Ruderman NB (1996). Differential stimulation of $\mathrm{Na}^{+}$pump activity by insulin and nitric oxide in rabbit aorta. American J ournal of Physiology, 270: H1287-H1293.

30. Herrera VLM, Chobanian AV \& Ruiz-Opazo $N$ (1988). Isoform specific modulation of $\mathrm{Na}^{+}, \mathrm{K}^{+}$-ATPase alpha-subunit gene expression in hypertension. Science, 241 : 221-223.

31. Liu X, Hymel LJ \& Songu-Mize E (1998). Role of $\mathrm{Na}^{+}$and $\mathrm{Ca}^{2+}$ in stretch-induced $\mathrm{Na}^{+}, \mathrm{K}^{+}$-ATPase $\alpha$-subunit regulation in aortic smooth muscle cells. American J ournal of Physiology, 274: H83-H89.

32. Book CBS, Wilson RP \& Ng YC (1994). Cardiac hypertrophy in the ferret increases expression of the $\mathrm{Na}^{+}, \mathrm{K}^{+}$-ATPase $\alpha_{1}$ - but not $\alpha_{3}$-isoform. American J ournal of Physiology, 266: H1221-H1227.

33. Leenen FHH, Harmsen E \& Yu H (1994). Dietary sodium and central vs peripheral ouabain-like activity in Dahl salt-sensitive vs salt-resistant rats. American J ournal of Physiology, 267: H1916-H1920.

34. Cabral AM \& Vasquez EC (1991). Time course of cardiac sympathetic and vagal tone changes in renovascular hypertensive rats. Hypertension, 4: 815-819.

35. Bissoli NS, Cicilini MA, Vasquez EC \& Cabral AM (2000). The diuretic chlorthalidone normalizes baroreceptor and Bezold$\mathrm{J}$ arisch reflexes in DOCA-salt hypertensive rats. Pharmacological Research, 41: 483-491.

36. Rodríguez-Mañas $L$, Sánchez-Ferrer CF, Pareja A, Casado MA, Arribas S, Salaices M \& Marín J (1994). Neurogenic component of ouabain-evoked contractions is modulated by the endothelium. Hypertension, 23: 10-17.

37. Leite R \& Salgado MCO (1992). Increased vascular formation of angiotensin II in onekidney, one clip hypertension. Hypertension, 19: 575-581.

38. Larivière $R$, Thibault $G \&$ Schiffrin $E L$ (1993). Incresed endothelin-1 content in blood vessels of deoxycorticosterone acetate-salt hypertensive but not in spontaneously hypertensive rats. Hypertension, 21: 294-300.

39. Abreu GR, Cabral AM, Futuro Neto HA \& Vasquez EC (1998). Ouabain produces diverse excitatory effects on afferent baroreceptor nerve activity in SHR and WKY animals. Clinical and Experimental Hypertension, 20: 85-94.

40. White RM, Rivera $\mathrm{CO} \&$ \&avison $\mathrm{CB}$ (1996). Differential contribution of endothelial function to vascular reactivity in conduit and resistance arteries from deoxycorticosterone-salt hypertensive rats. Hypertension, 27: 1245-1253. 